\title{
CDK4/6 inhibitors: a novel strategy for tumor radiosensitization
}

\author{
Yilan Yang ${ }^{1,2 \dagger}$, Jurui Luo ${ }^{1,2 \dagger}$, Xingxing Chen ${ }^{1,2}$, Zhaozhi Yang ${ }^{1,2}$, Xin Mei ${ }^{1,2}$, Jinli Ma ${ }^{1,2}$, Zhen Zhang ${ }^{1,2}$, \\ Xiaomao Guo ${ }^{1,2^{*}}$ and Xiaoli $\mathrm{Yu}^{1,2^{*}}$
}

\begin{abstract}
Recently, the focus of enhancing tumor radiosensitivity has shifted from chemotherapeutics to targeted therapies. Cyclindependent kinase 4 and 6 (CDK4/6) inhibitors are a novel class of selective cell cycle therapeutics that target the cyclin DCDK4/6 complex and induce G1 phase arrest. These agents have demonstrated favorable effects when used as monotherapy or combined with endocrine therapy and targeted inhibitors, stimulating further explorations of other combination strategies. Multiple preclinical studies have indicated that CDK4/6 inhibitors exhibit a synergistic effect with radiotherapy both in vitro and in vivo. The principal mechanisms of radiosensitization effects include inhibition of DNA damage repair, enhancement of apoptosis, and blockade of cell cycle progression, which provide the rationale for clinical use. CDK4/6 inhibitors also induce cellular senescence and promote anti-tumor immunity, which might represent potential mechanisms for radiosensitization. Several small sample clinical studies have preliminarily indicated that the combination of CDK4/6 inhibitors and radiotherapy exhibited well-tolerated toxicity and promising efficacy. However, most clinical trials in combined therapy remain in the recruitment stage. Further work is required to seek optimal radiotherapy-drug combinations. In this review, we describe the effects and underlying mechanisms of CDK4/6 inhibitors as a radiosensitizer and discuss previous clinical studies to evaluate the prospects and challenges of this combination.
\end{abstract}

Keywords: CDK4/6 inhibitor, Radiotherapy, Radiosensitivity

\section{Background}

Radiotherapy is one of the most important local control methods of malignant tumors. Approximately $50 \%$ of cancer patients receive radiotherapy during the treatment process [1]. However, the radioresistance of tumor cells limits the ability to reach a curative dose of radiation, which reduces radiotherapy efficacy and is more likely to cause local failures $[1,2]$. Substantial efforts have been made to improve the radiosensitivity via various types of radiation modulators. The early-stage radiosensitizers are mostly chemotherapeutic agents, such as cisplatin and 5fluorouracil, which have been demonstrated to enhance

\footnotetext{
*Correspondence: guoxm1800@163.com; stephanieyx|@hotmail.com

${ }^{+}$Yilan Yang and Jurui Luo contributed equally to this work.

'Department of Radiation Oncology, Fudan University Shanghai Cancer Center, 270 DongAn Road, Shanghai 200032, China

Full list of author information is available at the end of the article
}

radiosensitivity in head and neck squamous cell carcinoma (HNSCC), nasopharyngeal carcinoma (NPC), and gastrointestinal cancers [3]. These chemotherapeutics exhibit radiosensitization effects by increasing radiation damage and inhibiting DNA repair process $[4,5]$. However, due to the non-specific effects of chemotherapeutics, chemoradiation therapy increases the radiation toxicity of normal tissues as well [1]. Given the rapid development of targeted therapies, numerous studies of specific radiosensitizers are underway. CDK4/6 inhibitors are a novel class of selective cell cycle therapeutics that target the cyclin D-CDK4/6 complex and suppress activation of the downstream RBE2F pathway, thereby blocking cell cycle progression and inhibiting the tumor cell proliferation [6-8]. Multiple preclinical studies have demonstrated the radiosensitization effects of CDK4/6 inhibitors in various cancer types. In this review, we focus on the molecular basis and the

C C The Author(s). 2020 Open Access This article is licensed under a Creative Commons Attribution 4.0 International License, which permits use, sharing, adaptation, distribution and reproduction in any medium or format, as long as you give appropriate credit to the original author(s) and the source, provide a link to the Creative Commons licence, and indicate if changes were made. The images or other third party material in this article are included in the article's Creative Commons. licence, unless indicated otherwise in a credit line to the material. If material is not included in the article's Creative Commons licence and your intended use is not permitted by statutory regulation or exceeds the permitted use, you will need to obtain permission directly from the copyright holder. To view a copy of this licence, visit http://creativecommons.org/licenses/by/4.0/ The Creative Commons Public Domain Dedication waiver (http://creativecommons.org/publicdomain/zero/1.0/) applies to the data made available in this article, unless otherwise stated in a credit line to the data. 
underlying mechanisms regarding the efficacy of CDK4/6 inhibitors with radiotherapy to provide a strong rationale for clinical utilization of the combined therapy.

\section{Overview of CDK4/6 inhibitors}

\section{Role of CDK4/6 in $\mathrm{G}_{1}-\mathrm{S}$ transition}

CDK4/6 plays a critical role in the $\mathrm{G}_{1}-\mathrm{S}$ checkpoint, which governs genome replication in the cell cycle $[9,10]$ (Fig. 1). From the classical view, the retinoblastoma (RB) protein, as a negative cell cycle regulator, binds to the transcription factor E2F to repress the transcriptional activity in the early $\mathrm{G}_{1}$ phase $[9,11]$. Mitogenic stimuli induce increased expression levels of D-type cyclins, which form complexes with CDK4/6 to phosphorylate RB [9]. Hypophosphorylated RB partially relieves the inhibitory control of the E2F transcription factor family; promotes the expression of E2F target genes, such as cyclin $\mathrm{E}$; and facilitates the $\mathrm{G}_{1}$ phase progression $[9,11,12]$. In the late $G_{1}$ phase, CDK2 is activated as cyclin $\mathrm{E}$ levels increase. The continuous formation of the cyclin E-CDK2 complex hyperphosphorylates and inactivates $\mathrm{RB}$ proteins, which results in the release of E2F transcription factors, initiation of transcription, and increased expression of S phase genes $[9,12]$. Thereby, the cell cycle proceeds from the late $G_{1}$ to $S$ phase normally. During the $\mathrm{G}_{1}-\mathrm{S}$ transition, CDK4/6 activity is regulated by Cip/Kip (p21 cip1, $\mathrm{p} 27^{\text {kip1 }}$, and $\mathrm{p} 57^{\text {kip2}}$ ) family and Ink4 family ( $\mathrm{p} 16^{\text {Ink4a }}, \mathrm{p} 15^{\text {Ink4b }}, \mathrm{p} 18^{\text {Ink4c }}$, and $\mathrm{p} 19^{\text {Ink4d }}$ ) proteins. The Cip/Kip family broadly inhibits the cyclin-CDK complex activity, also known as pan-CDK inhibitors [10, 12]. Conversely, Ink 4 family proteins specifically bind to CDK4/6 to inactivate the kinase, thus inducing the inhibition of RB phosphorylation and blockade of cell cycle progression $[8,9,13]$. CDK4/6 inhibitors exert similar tumorsuppressing functions as Ink4 family members [12]. All three CDK4/6 inhibitors bind to the ATP domain of CDK4/6, but their targets are slightly different [14] (Fig. 2).

\section{Therapeutic applications of CDK4/6 inhibitors}

The cyclin D-CDK4/6-RB pathway is frequently dysregulated in many cancers [12]. Moreover, increased levels of D-type cyclins and CDK4 are commonly observed [15-17], which makes inhibitors targeting the cyclin D-CDK4/6-RB pathway ideal candidates for cancer therapeutics. When used as monotherapy, CDK4/6 inhibitors exhibit certain

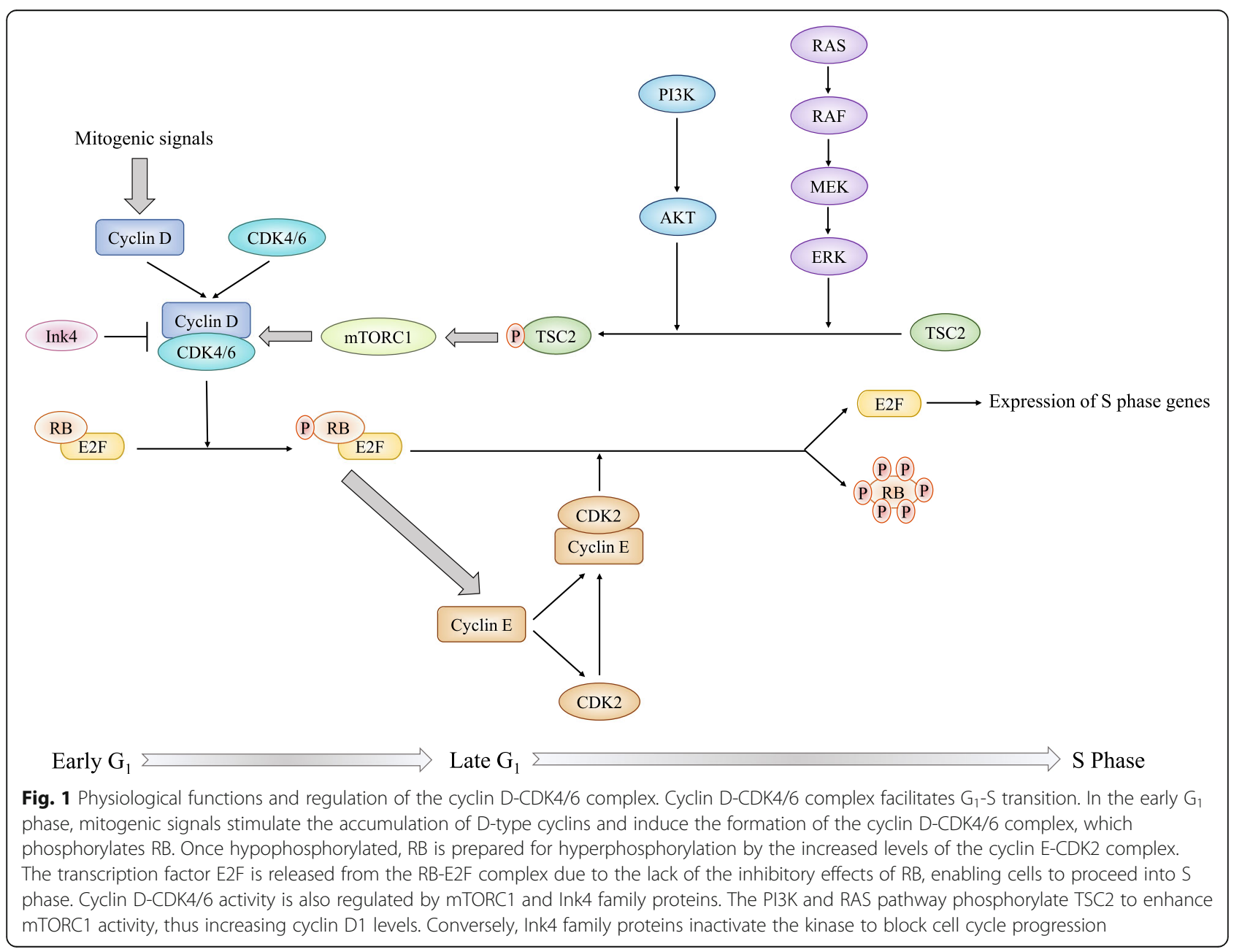




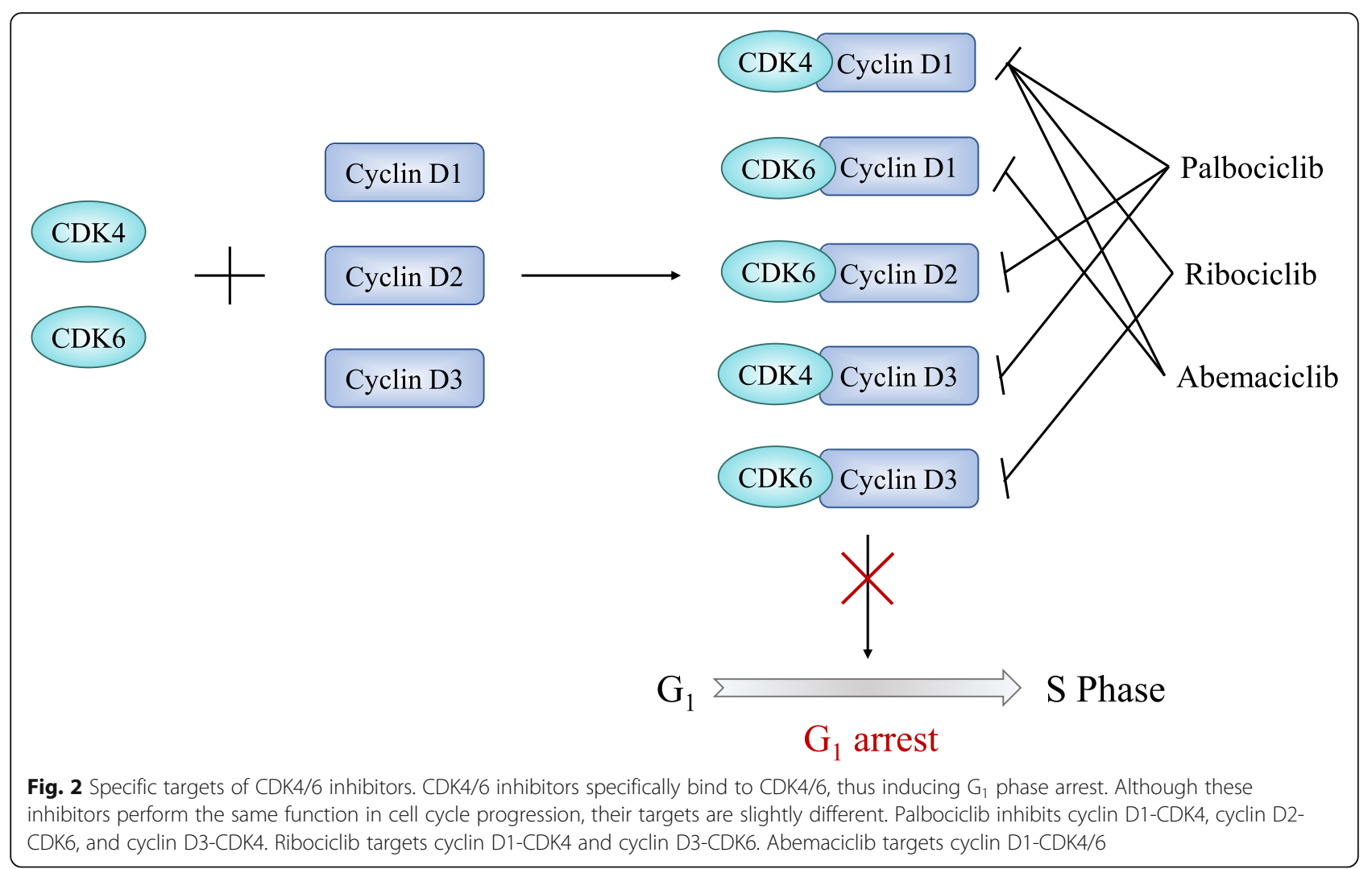

efficacy in solid tumors, such as non-small cell lung cancer (NSCLC) [18, 19] and mature teratoma [20]. Moreover, CDK4/6 inhibitors in combined therapies displayed better prospects. Palbociclib, ribociclib, and abemaciclib have been approved by the Food and Drug Administration for advanced hormone receptor-positive $(\mathrm{HR}+)$ breast cancer patients when combined with letrozole or fulvestrant [12, 13]. The combinatorial strategy presented a substantial improvement in progression-free survival with a well-tolerated toxicity profile in multiple clinical trials [21-26]. The combination of CDK4/6 inhibitors and other targeted drugs also shows promising prospects. PI3K-AKT-mTOR and RASRAF-MEK-ERK pathway inhibitors both exhibit synergistic tumor suppression effects with CDK4/6 inhibitors in many preclinical models [27-32]. An important mechanism is that activation of oncogenic PI3K and RAS pathways is correlated with the cyclin D-CDK4/6 complex [8, 33]. RAS pathway drives CCND1 mRNA transcription and enhances cyclin D-CDK4/6 activity [34]. Hence, PI3K and RAS pathway inhibitors in combination with CDK4/6 inhibitors produce a double-hit on cyclin D-CDK4/6 activity [9]. Moreover, CDK4/6, PI3K, and RAS pathways intersect via tuberous sclerosis complex 2 (TSC2)(Fig. 1), which is a negative regulator of mammalian target of rapamycin complex 1 (mTORC1) $[9,33]$. The PI3K and RAS pathway activate mTOR signaling through phosphorylating TSC2, and CDK4/6 can directly bind to and phosphorylate TSC2 [33,
35]. Therefore, co-inhibition of the PI3K or RAS pathway with the CDK4/6 pathway leads to a synergistic suppression of TSC2 phosphorylation and thus decreases mTORC1 activity [36]. This action might represent another critical mechanism for the synergy of CDK4/6 inhibitors with PI3K or RAS pathway inhibitors.

Although CDK4/6 inhibitors have achieved some clinical success, the lack of predictive biomarkers is a major obstacle preventing CDK4/6 inhibitors from better efficacy. Currently, a majority of research focuses on the potential biomarkers of breast cancer, and the HRpositive status remains the only clinically used biomarker. However, HR expression levels as a biomarker showed no clear survival advantage in the phase III PALOMA-3 trial $[13,25]$. Several potential biomarkers, such as CCND1, CDKN2A, and RB1, exhibit an association with the sensitivity of CDK4/6 inhibitors in preclinical studies [12, 13, 37]. The most reliable of these biomarkers is RB1 since amplification of CCND1 and loss of CDKN2A showed no difference in benefit in the phase II PALOMA-1/TRIO-18 study [38]. Loss of RB1 appears to induce resistance of CDK4/6 inhibitors in many in vitro studies, but this finding has yet to be confirmed clinically [12, 37]. Nevertheless, the lack of RB1 expression is rare in ER-positive breast cancer patients, leaving no appropriate biomarkers other than the HR status [39]. However, there are a few ongoing clinical 
trials specifically targeting the molecular drivers of tumors, such as Lung-MAP (NCT02154490) and SIGN ATURE (NCT02187783) trials, in which patients are being allocated based on CCND, CDKN2A, or CDK4 aberrations. More data regarding the verification of various biomarkers will be available after the completion of these ongoing clinical trials.

\section{Preclinical studies of CDK4/6 inhibitors as radiosensitizers}

In addition to intersecting with ER, PI3K, and RAS pathways, the cyclin D-CDK4/6-RB pathway is also involved in DNA damage repair (DDR) [40], which makes CDK4/ 6 inhibitors perfect candidates for tumor radiosensitization. Numerous in vitro and in vivo data have validated the radiosensitization effects of CDK4/6 inhibitors.

\section{In vitro experimental data}

CDK4/6 inhibitors enhance the radiosensitivity in multiple cell lines. The combination therapy significantly inhibits single-cell colony formation with a sensitizer enhancement ratio (SER) of 1.1-2.3 (Table 1). The radiosensitization effect is quite outstanding in malignant brain cancer cell lines. Two medulloblastoma cell lines, Daoy and ONS-76, were administered different doses of radiation following 48 $h$ of treatment with palbociclib. The enhancement ratio ranged from 1.6 to 2.3 at $10 \%$ survival [41]. Moreover, the combination not only decreases colony numbers but also reduces the tumor sphere formation ability [45]. The tumor sphere formation ability is associated with cancer stem cell properties, which includes increased radiation resistance [50, 51]. Huang et al. [45] reported that the combination of 6 Gy radiation and $5 \mu \mathrm{M}$ palbociclib dramatically reduced tumor sphere formation in Huh7 (hepatocellular carcinoma, HCC) cells compared to ionizing radiation (IR) alone. The combined therapy significantly inhibited radiationinduced cell growth and reduced radiation resistance.

Additionally, although palbociclib, ribociclib, and abemaciclib resemble each other structurally, the three drugs exhibit different radiosensitization effects. Naz et al. [44] demonstrated that palbociclib and ribociclib failed to promote radiation sensitivity in $\mathrm{H} 460$ (NSCLC) cells when

Table 1 In vitro experimental data of radiosensitization effects

\begin{tabular}{|c|c|c|c|}
\hline Authors & CDK4/6 inhibitor & Human cell line & Efficacy with radiotherapy \\
\hline Whiteway et al. [41] & Palbociclib & $\begin{array}{l}\text { Medulloblastoma } \\
\text { (Daoy) } \\
\text { (ONS-76) }\end{array}$ & $\begin{array}{l}\mathrm{SF}_{2}{ }^{\mathrm{a}} \downarrow \\
\mathrm{SER}_{10}{ }^{\mathrm{b}} 1.6, \mathrm{SER}_{50}{ }^{\mathrm{c}} 1.5 \\
\mathrm{SER}_{10} 2.3, \mathrm{SER}_{50} 2.3\end{array}$ \\
\hline Hashizume et al. [42] & Palbociclib & $\begin{array}{l}\text { Intracranial ATRT }{ }^{d} \\
\text { (BT12) } \\
\text { (BT16) }\end{array}$ & $\begin{array}{l}\text { DEF }^{\text {e }} 1.16-1.60 \\
\text { DEF } 1.18-1.70\end{array}$ \\
\hline Whittaker et al. [43] & Palbociclib & $\begin{array}{l}\text { Glioblastoma } \\
\text { (GBM-L1, HW1, RN1, BAH1) }\end{array}$ & Colony numbers drop to zero \\
\hline Naz et al. [44] & Abemaciclib & $\begin{array}{l}\text { NSCLC } \\
\text { (A549, H460, H820, H1975) }\end{array}$ & $\operatorname{DMF}^{f} 1.30-1.71$ \\
\hline Tao et al. [30] & Palbociclib and Trametinib & $\begin{array}{l}\text { NSCLC } \\
(\text { A549, H460) }\end{array}$ & $\begin{array}{l}\text { Cell survival fraction } \downarrow \\
\text { Apoptosis } \uparrow\end{array}$ \\
\hline Huang et al. [45] & Palbociclib & $\begin{array}{l}\text { HCC (Hep3B, Huh7) } \\
\text { CCA }^{9} \text { (HuCCT1) }\end{array}$ & $\begin{array}{l}\text { Tumor sphere numbers } \downarrow \\
\text { Colony numbers } \downarrow\end{array}$ \\
\hline Xie et al. [46] & Palbociclib & $\begin{array}{l}\text { NPC } \\
\text { (CNE-1) } \\
(\text { CNE-2) }\end{array}$ & $\begin{array}{l}\mathrm{SF}_{2} \downarrow \\
\mathrm{SER} 1.118-1.475 \\
\text { SER } 1.10-1.20\end{array}$ \\
\hline Gottgens et al. [47] & Palbociclib & $\begin{array}{l}\text { HNSCC } \\
\text { (UT-SCC-24A) }\end{array}$ & SER 1.36-1.60 \\
\hline Tai et al. [48] & Ribociclib & $\begin{array}{l}\text { HNSCC } \\
\text { (OML1, OML1-R) }\end{array}$ & $\begin{array}{l}\text { Colony numbers } \downarrow \\
\text { Cell viability } \downarrow\end{array}$ \\
\hline Fernández-Aroca et al. [49] & Palbociclib & $\begin{array}{l}\text { Breast cancer (MCF-7) } \\
\text { Lung cancer (A549) } \\
\text { Colorectal cancer (HCT116) }\end{array}$ & Cell survival fraction $\downarrow$ \\
\hline Li et al. [50] & Ribociclib and CA3 & $\begin{array}{l}\text { EAC }^{\mathrm{h}} \\
\text { (Flo-1 XTR) }\end{array}$ & Colony numbers $\downarrow$ \\
\hline
\end{tabular}

$\mathrm{SF}_{2}$, survival fraction at $2 \mathrm{~Gy}$

${ }^{b} \mathrm{SER}_{10}$, sensitizer enhancement ratio at $10 \%$ survival

c $\mathrm{SER}_{50}$, sensitizer enhancement ratio at $50 \%$ survival

d ATRT, atypical teratoid rhabdoid tumor

e $D E F$, radiation dose enhancement factor

${ }^{f} \mathrm{DMF}$, radiation dose modifying factor

g CCA, cholangiocarcinoma

${ }^{\mathrm{h}} \mathrm{EAC}$, esophageal adenocarcinoma 
added either pre- or post-IR treatment. In contrast, abemaciclib exhibited enhancement of radiosensitivity in the majority of NSCLC cell lines when added post-IR, including H460. CDK4/6 inhibitors probably have different radiosensitization effects, and the underlying mechanisms should be assessed in further investigations.

\section{In vivo experimental data}

In vivo preclinical studies have further verified the radiosensitization effects of CDK4/6 inhibitors, including prolonging the median survival time, reducing tumor volume, and delaying tumor regeneration (Table 2). Several in vivo studies demonstrated that palbociclib in combination with IR increased the median survival time by 1.2- to 3.3-fold in mice with brain malignancy xenografts [42, 43, 52]. The combined therapy also dramatically reduced the tumor weight and volume without no obvious systemic toxicity as assessed by mouse body weight $[30,45,50]$. The Ki67 staining in xenografts was drastically reduced, revealing the reduction of tumor proliferation $[30,44,50]$.

\section{Mechanisms of CDK4/6 inhibitors as radiosensitizers}

\section{Inhibition of DNA damage repair}

The impairment of DDR is an essential determinant of CDK4/6 inhibitor-associated radiosensitization in human cell lines. IR produces cytotoxic effects on DNA, which mainly results in DNA single-strand breaks (SSBs) and double-strand breaks (DSBs) [53]. Unrepaired and inaccurate-repaired DNA DSBs are the main cause of radiation-induced cell death [54]. Multiple preclinical studies have demonstrated that IR increases $\gamma$-H2AX and 53BP1 levels in a dose dependent manner and increases DNA DSBs [30,42, 44-47]. $\gamma-\mathrm{H} 2 \mathrm{AX}$ is one of the earliest events of DDR with the induction of DSB [55]. The abundance of $\gamma-\mathrm{H} 2 \mathrm{AX}$ foci reaches a peak at $30 \mathrm{~min}$ after IR and returns to baseline levels approximately $24 \mathrm{~h}$ post-IR [37]. In addition, 53BP1 plays a similar role to $\gamma-\mathrm{H} 2 \mathrm{AX}$ in most cases [45], which is also a crucial hallmark of IR-induced DSBs [56]. Naz et al. [44] investigated $\gamma$-H2AX foci in $\mathrm{H} 460$ and $\mathrm{H} 1299$ (NSCLC) cells following 7.5 Gy irradiation. The $\gamma$-H2AX level rapidly increased in H460 (7.9-fold) and H1299 (6.7-fold) cells $0.5 \mathrm{~h}$ after IR compared to untreated control. Additional studies also demonstrated that various post-irradiated cell lines showed substantial increases in $\gamma$-H2AX and (or) 53BP1 foci, which eventually led to increased DSBs [37, 42, 45-47, 49].

$\gamma$-H2AX and 53BP1 levels decrease over time, reflecting the dynamic process of DDR. The combination of IR and CDK4/6 inhibitors causes marked retention of $\gamma$ H2AX and (or) 53BP1 levels, thus delaying DSB repair to enhance radiotherapy efficacy [42, 44-47]. With 7.5 Gy and $10 \mu \mathrm{M}$ abemaciclib, $\gamma-\mathrm{H} 2 \mathrm{AX}$ levels were increased 3.92 -fold at $24 \mathrm{~h}$ in $\mathrm{H} 460$ cells. However, the levels were only 0.97 -fold in H1299 cells (radiation-resistant), which was basically equivalent to the level before irradiation [44]. Huang et al. [45] reported similar findings in HuCCT1 (CCA), Huh7, and Hep3B (HCC) cells. These post-IR cells treated with $5 \mu \mathrm{M}$ palbociclib sustained higher levels of $\gamma-\mathrm{H} 2 \mathrm{AX}$ and 53BP1 at $24 \mathrm{~h}$ compared with DMSO-treated cells. Several other studies also supported this view that CDK4/6 inhibitors exhibited cellular radiosensitivity by increasing unrepaired DSBs and inducing the delayed repair kinetics of DSBs [42, 46, 47].

Table 2 In vivo experimental data of radiosensitization effects

\begin{tabular}{|c|c|c|c|}
\hline Authors & CDK4/6 inhibitor & Xenograft & Efficacy with radiotherapy \\
\hline $\begin{array}{l}\text { Hashizume et al. } \\
\text { [42] }\end{array}$ & Palbociclib & $\begin{array}{l}\text { Intracranial ATRT } \\
\text { (BT12) } \\
\text { (BT16) } \\
\text { Glioblastoma } \\
\text { (GBM43) }\end{array}$ & $\begin{array}{l}\text { Median survival time increased by } 24 \text { to } 26 \text { days ( } 1.4 \text {-fold) } \\
\text { Median survival time increased by } 31.5 \text { to } 34.5 \text { days ( } 3.3 \text {-fold) } \\
\text { Median survival time increased by } 10 \text { to } 13.5 \text { days ( } 1.6 \text {-fold) }\end{array}$ \\
\hline $\begin{array}{l}\text { Whittaker et al. } \\
\text { [43] }\end{array}$ & Palbociclib & $\begin{array}{l}\text { Glioblastoma } \\
\text { (RN1) }\end{array}$ & Median survival time increased by 8 days \\
\hline Naz et al. [44] & Abemaciclib & $\begin{array}{l}\text { NSCLC } \\
(\mathrm{H} 460)\end{array}$ & $\begin{array}{l}\text { Tumor regrowth delay } 8 \text { and } 9 \text { days, inhibit IR-induced tumor } \\
\text { vasculogenesis }\end{array}$ \\
\hline Tao et al. [30] & $\begin{array}{l}\text { Palbociclib and } \\
\text { Trametinib }\end{array}$ & $\begin{array}{l}\text { NSCLC } \\
\text { (A549) }\end{array}$ & $\begin{array}{l}\text { Tumor volume } \downarrow \\
\text { Proliferation } \downarrow \\
\text { Apoptosis } \uparrow\end{array}$ \\
\hline Huang et al. [45] & Palbociclib & $\begin{array}{l}\mathrm{HCC} \\
(\text { Huh7) }\end{array}$ & $\begin{array}{l}\text { Tumor volume } \downarrow \\
\text { Tumor weight } \downarrow\end{array}$ \\
\hline Li et al. [50] & Ribociclib and CA3 & $\begin{array}{l}\text { EAC } \\
\text { (Flo-1 XTR) }\end{array}$ & $\begin{array}{l}\text { Tumor volume } \downarrow \\
\text { Tumor weight } \downarrow\end{array}$ \\
\hline Barton et al. [52] & Palbociclib & $\begin{array}{l}\text { Ink4a-ARF- deficient BSG }{ }^{\text {a }} \text { mouse } \\
\text { model }\end{array}$ & Median survival time increased by 10 days (19\%) \\
\hline
\end{tabular}

a BSG, brainstem glioma 
The combination of CDK4/6 inhibitors and IR not only increases DSBs and delays the DSB repair but also causes homologous recombination (HR) deficiency by decreasing the expression of $\operatorname{Rad} 51$ and ataxia telangiectasia mutated (ATM) kinase [57]. HR and nonhomologous end joining (NHEJ) are the two principal pathways in DSB repair, and the latter plays a dominant role in IR-induced DDR $[55,58]$. The DNA recombinase Rad51 is a pivotal component of the HR pathway, and the fraction of Rad51 foci increases during the HR process [47]. ATM kinase, the upstream regulator of Rad51, is activated to enhance HR in response to DSBs [55, 57]. In UT-SCC-24A (HNSCC) cells, palbociclib combined with IR reduced the expression of $\operatorname{Rad} 51$ approximately 3.5-fold [47]. Palbociclib also impaired ATM kinase activation by reducing phosphorylation of ATM kinase and its downstream targets with $10 \mathrm{~Gy}$ irradiation in both HCC and CCA cells [45]. However, impairment of the HR pathway appeared to be dependent on a functional p53 or RB status. Abemaciclib and IR decreased the formation of Rad51 foci markedly in H460 (p53-proficient) cells. Nevertheless, no significant changes were observed in H1299 (p53-deficient) cells [44]. A possible explanation was that p53 is a key effector in IR-induced cellular response and the lack of p53 was associated with increased radioresistance [59]. This hypothesis was confirmed by Fernández-Aroca et al. [49], who reported that p53 was a critical determinant of palbociclib-associated radiosensitivity. Dean et al. [37] shared similar findings in breast cancer given that the response of Rad51 to palbociclib with IR presented in an RB-dependent manner. Palbociclib pretreatment led to complete inhibition of Rad51 foci accumulation in MDA-MB-231 and Hs578t (RB-proficient) cells but not in MDA-MB-468 (RB-deficient) cells. Furthermore, $500 \mathrm{nM}$ palbociclib caused an approximately $60 \%$ decrease in HR-mediated DSB repair and 2.5 -fold increase in relative NHEJ activity, indicating that CDK4/6 inhibition augmented NHEJ efficiency [37]. However, current data are not available to demonstrate that CDK4/6 inhibitors with IR enhance NHEJ activity while weakening the HR efficiency. More studies are currently underway to elucidate this relationship.

\section{Enhancement of apoptosis}

As mentioned above, radiotherapy induces massive DSBs. As the intracellular stimulus, IR-induced DNA damage mediates most radiosensitivity-associated proapoptotic effects [60]. Several preclinical studies investigated apoptotic changes in combined therapy. Huang et al. [45] showed that $8 \mathrm{~Gy}$ irradiation plus $20 \mu \mathrm{M}$ palbociclib resulted in remarkably increased DNA fragmentations (a hallmark of apoptosis) in HCC and CCA cells compared with monotherapy. Another study also reached similar conclusions in NPC cells, demonstrating that palbociclib treatment after irradiation prominently elevated the proportion of apoptotic cells in comparison with IR alone (CNE-1, 19.6\% versus 10.685\%; CNE-2, $21.655 \%$ versus $12.635 \%$ ). Mechanistically, they demonstrated that the combination augmented the mitochondrial reactive oxygen species (ROS) level, which is regarded as an apoptosis mediator in radiotherapy or chemotherapy, thus enhancing apoptosis [46]. Interestingly, Hagen et al. [61] reported that palbociclib induced anti-apoptosis effects in irradiated MCF10A (normal human mammary epithelial cell) and MDA-MB-231 (triple-negative breast cancer, TNBC) cells by reducing cleaved PARP levels. The reason why the investigators reached the opposite conclusion remains unclear, but the radiotherapy-drug combination strategy and the p53 status of different cell lines could be an explanation.

\section{Blockade of cell cycle progression}

Another critical determinant of radiosensitivity is cell cycle arrest since CDK4/6 inhibitors induce significant $\mathrm{G}_{1}-\mathrm{S}$ arrest [11]. Meanwhile, $\mathrm{G}_{2}-\mathrm{M}$ phase cells are the most sensitive to radiation [4]. Tai et al. [48] found that 4 Gy irradiation in combination with ribociclib caused evident $\mathrm{G}_{1}-\mathrm{S}$ arrest in HNSCC cells as the ratio of OML1 cells in the $G_{1}$ phase increased from 48.6 to $69.4 \%$ after treatment and similar effects were observed in radioresistant OML1-R cells. Xie et al. [46] demonstrated that concurrent palbociclib with IR and radiotherapy followed by palbociclib in NPC cells conspicuously increased the $G_{2}$ $M$ cell proportion and decreased radioresistant $G_{1}$ cells, suggesting that the combination therapy also caused $\mathrm{G}_{2^{-}}$ $M$ arrest. Furthermore, the combined regimens not only blocked $G_{1}-S$ and $G_{2}-M$ checkpoint but also suppressed mitosis. Gottgens et al. [47] investigated the changes in phosphorylated histone $3(\mathrm{p}-\mathrm{H} 3)$ at Ser10 in UT-SCC24A (HNSCC) cells in response to IR and palbociclib. Phospho-H3 (Ser10) is associated with chromosome condensation, which is a major event during mitosis [62]. After IR alone, p-H3 (Ser10) levels dropped rapidly and returned to normal at $24 \mathrm{~h}$. In contrast, p-H3 (Ser10) depleted quickly without rebound after combing palbociclib and IR, indicating a decreased number of mitotic cells and inhibition of mitosis. Intriguingly, Hagen et al. [61] reported that knockdown of CDK4 did not affect cell cycle as no marked changes in cell cycle distribution were observed after IR in shCDK4 cells. A possible explanation is that silencing CDK4 and CDK4/6 inhibitors display different outcomes in terms of cell cycle progression. In general, CDK4/6 inhibitors in combination with IR provide a strong blockade of cell cycle progression, which is a critical mechanism of radiosensitivity. 


\section{Other potential mechanisms}

In addition to the classic radiosensitization mechanisms mentioned above, CDK4/6 inhibitors also induce other biological phenotypes, providing mechanistic foundations for the combination of CDK4/6 inhibitors and radiotherapy.

First, long-term exposure to CDK4/6 inhibitors induces the cellular senescence phenotype in many cancer cell lines, such as breast cancer [63], neuroblastoma [64], and melanoma [65]. It is not surprising as CDK4/6 inhibitors play a similar role to $\mathrm{p} 16^{\text {Ink4a }}$, and the $\mathrm{p} 16^{\text {Ink4a }}$ RB pathway is one of the most important mechanisms of cellular senescence $[66,67]$. Persistent CDK4/6 inhibition suppresses RB phosphorylation and downstream transcription activities to induce an irreversible arrest of cell proliferation, which is also known as cellular senescence $[68,69]$. After 8 days exposure of palbociclib, the fraction of senescence-associated $\beta$-galactosidase (SA- $\beta$ gal)-positive cells was significantly increased in $1205 \mathrm{Lu}$ (melanoma) cells [65]. Ribociclib also yielded similar results in neuroblastoma cell lines [64]. On the other hand, radiotherapy triggers premature senescence in solid tumor cell lines [70]. This finding is attributed to the fact that IR causes massive lesions in DNA, therefore activates the ATM-Chk2-p53-p21 axis (senescence-associated DDR pathway), leading to persistent cell cycle arrest and cellular senescence [68]. In addition, 8 or $10 \mathrm{~Gy}$ irradiation accelerated cellular senescence in TP53 wildtype tumor cell lines based on increased SA- $\beta$-gal positivity $[70,71]$. Accordingly, radiotherapy and CDK4/6 inhibitors may synergistically induce tumor cell senescence and further inhibit tumor progression.

Senescent cells secrete inflammatory cytokines, chemokines, and growth factors, which collectively comprise the the senescence-associated secretory phenotype (SASP) $[67,68]$. After treatment with palbociclib for 8 days, SASP components, such as interleukin-6 (IL-6), interleukin-8 (IL-8), and chemokine (C-X-C motif) ligand 1 (CXCL1), secreted by $1205 \mathrm{Lu}$ cells substantially increased [65]. Furthermore, radiation triggers the release of cytoplasmic DNA and activates the cyclic GMPAMP synthase (cGAS)-stimulator of interferon genes (STING) pathway, which plays a pivotal role in SASP production [72, 73]. Thus, the combination of CDK4/6 inhibitors and radiation could theoretically induce SASP, which affects the immune response [72]. On one hand, SASP recruits immune cells to stimulate the adaptive immune response and eliminate senescent tumor cells. On the other hand, SASP also attracts immunosuppressive cells and creates a protumorigenic environment [72]. Although SASP is usually regarded as a "doubleedged sword", it still provides a novel perspective for radiosensitization mechanisms. Thus, the combination of CDK4/6 inhibitors and radiotherapy may exert radiosensitization effects through immunomodulation.
Indeed, several investigators have demonstrated that CDK4/6 inhibitors exhibited direct immunostimulatory effects in both tumor and immune cells [74]. In tumor cells, CDK4/6 inhibitors suppressed the RB-E2FDNMT1 axis, which activated endogenous retroviral elements and increased double-stranded RNA levels. This action subsequently induced a type III interferon response and upregulated tumor antigen presentation [75]. On the other hand, radiotherapy enhances MHC class I expression by activating the mTOR pathway [76]. Moreover, radiation elicits activation of dendritic cells (DCs) and enhances cross-presentation of tumor antigens [73, 76]. Gupta et al. [77] reported that the expression of CD70 and CD86 (co-stimulatory molecules) on DCs was significantly increased after $10 \mathrm{~Gy}$ irradiation. In immune cells, CDK4/6 inhibitors promoted $\mathrm{T}$ cell activation via enhancing nuclear factor of activated $\mathrm{T}$ cells (NFAT) transcriptional activity and interleukin-2 (IL-2) production $[78,79]$. On the other hand, radiation-induced $\mathrm{T}$ cell activation has been demonstrated in several preclinical studies, which is mediated by the induction of viral mimicry and activation of the cGAS-STING pathway [80-82]. Although IR recruits regulatory T cells (Treg) and other immunosuppressive cells to the tumor microenvironment, CDK4/6 inhibitors markedly reduce the proliferation of Tregs [75]. Collectively, CDK4/6 inhibitors and radiotherapy may synergistically exert an antitumor immune response by enhancing antigen presentation capacity and $\mathrm{T}$ cell activation. These potential mechanisms offer new perspectives for future exploration. The combination of CDK $4 / 6$ inhibitors and radiation may not only improve local tumor control but also enhance systemic disease control, providing the possibility for the triplet combination of CDK4/6 inhibitors, radiotherapy and immunotherapy.

\section{Clinical studies of CDK4/6 inhibitors in combination with radiotherapy}

Multiple preclinical data suggest a potential synergistic effect when CDK4/6 inhibitors and radiotherapy are administered concurrently. However, safety and efficacy still require further investigations. Currently, there are six ongoing clinical trials (Table 3 ) as well as several small sample clinical studies (Table 4), which mostly target $\mathrm{HR}+$ / HER2- metastatic breast cancer (MBC) patients. The preliminary results [83-86] propose that no significantly increased toxicity is observed, indicating that the combined therapy is promising as a novel strategy. Ippolito et al. [84] reported that hematological toxicity neutropenia is most common among all adverse events. In total, $60 \%$ of patients experienced grade 3 or greater neutropenia before combination treatment, suggesting that we should carefully evaluate previous toxicity to prevent reoccurrence. Figura et al. [85] retrospectively analyzed 42 lesions in 15 
Table 3 Clinical trials with CDK4/6 inhibitors in combination with IR

\begin{tabular}{|c|c|c|c|c|c|}
\hline Cancer Type & Phase & Arm & $\mathrm{n}$ & Status & NCT \\
\hline $\mathrm{HGG}^{\mathrm{a}}$, DIPG ${ }^{\mathrm{b}}$, bithalamic HGG & $|/| \mid$ & Ribociclib + IR & 24 & Active, not recruiting & NCT02607124 \\
\hline Glioma (HGG, DIPG et al.) & । & Ribociclib + Everolimus + IR & 24 & Recruiting & NCT03355794 \\
\hline Locally advanced HNSCC & $|/| \mid$ & Palbociclib + Cetuximab + IMRT $^{c}$ & 33 & Recruiting & NCT03024489 \\
\hline HPV-unrelated HNSCC & $\|$ & Palbociclib + Cetuximab or Cisplatin + IMRT & 29 & Recruiting & NCT03389477 \\
\hline $\begin{array}{l}\text { Bone metastatic breast cancer } \\
(\mathrm{HR}+/ \mathrm{HER} 2-)\end{array}$ & $\|$ & Palbociclib + Hormone therapy $+\mathbb{I R}$ & 42 & Recruiting & NCT03691493 \\
\hline Metastatic breast cancer (HR+/HER2-) & $\|$ & Palbociclib + Letrozole \pm SBRT $^{d}$ & 204 & Not yet recruiting & NCT04220476 \\
\hline
\end{tabular}

${ }^{\mathrm{a}} \mathrm{HGG}$, high-grade glioma

${ }^{b}$ DIPG, diffuse intrinsic pontine glioma

c IMRT, intensity-modulated radiation therapy

d SBRT, stereotactic body radiation therapy

brain MBC patients. Two lesions (5\%) developed radiation necrosis, and both of them underwent four previous RT courses before the occurrence of radionecrosis, indicating the significance of cautious assessment of the treatment plan margins. Chowdhary et al. [86] reported that concomitant treatment with palbociclib and RT resulted in grade 1 or 2 toxicity and notably relieved pain. Also, no local failure was noted in evaluable follow-up patients.

Given these results, the combined treatment seems welltolerated, whereas severe adverse effects may be a concern. A breast cancer patient with supraclavicular lymph node metastasis was reported to develop grade 3 radiation esophagitis and dermatitis after receiving palbociclib with 40 Gy in 20 fractions to the left neck [87]. Another case was a breast cancer patient with bone metastases at the left iliac bone and first sacral vertebrae. This patient experienced radiation-induced grade 3 enterocolitis after administration of palbociclib and $30 \mathrm{~Gy}$ in 10 fractions to pelvic bones, which might be related to the over-sensitization after palbociclib administration [88]. Hence, combination therapy should be used cautiously until more data are available. In addition, the patient's condition should be thoroughly evaluated and treated individually before the utilization of combination regimens.

\section{Conclusions}

CDK4/6 inhibitors have greatly changed the treatment landscape of HR-positive breast cancer patients, stimulating further explorations of combination therapy. Significant preclinical data have demonstrated the radiosensitization effects of CDK4/6 inhibitors via inhibiting DDR, enhancing apoptosis, and blocking cell cycle progression. CDK4/6 inhibitors also induce cellular senescence and promote anti-tumor immunity, which might be potential mechanisms for clinical radiosensitization. Although several clinical studies have presented welltolerated toxicity and promising efficacy for combination therapy, safety remains a major concern. Radiotherapy is currently used as palliative treatment in clinical trials, and most patients have already received irradiation in previous treatment processes. Therefore, re-irradiation is likely to cause cumulative toxicity and severe adverse events. In addition to palliative treatment, radiotherapy can also be used as a postoperative adjuvant treatment

Table 4 Case reports and clinical studies with CDK4/6 inhibitors in combination with IR

\begin{tabular}{|c|c|c|c|c|}
\hline Authors & Patients & Arm & Toxicity & Efficacy \\
\hline $\begin{array}{l}\text { Hans et al. } \\
\text { [83] }\end{array}$ & $\begin{array}{l}\text { Metastatic breast } \\
\text { cancer } \\
(\text { HR+/HER2-) } \\
n=5\end{array}$ & $\begin{array}{l}\text { Palbociclib + Fulvestrant } \\
+ \text { palliative IR }\end{array}$ & $\begin{array}{l}\text { Digestive toxicity: mucositis (grade } 1=20 \% \text {, grade } 2=20 \% \text { ) } \\
\text { Hematological toxicity: grade } 3 \text { neutropenia = } 40 \% \text {, grade } \\
3 \text { anemia }=20 \% \text {, grade } 3 \text { thrombopenia }=40 \% \\
\text { No skin toxicity }\end{array}$ & $\begin{array}{l}\text { Symptom control and } \\
\text { pain relief (100\%) }\end{array}$ \\
\hline $\begin{array}{l}\text { Ippolito et al. } \\
\text { [84] }\end{array}$ & $\begin{array}{l}\text { Metastatic breast } \\
\text { cancer } \\
(\mathrm{HR}+) \\
n=16\end{array}$ & $\begin{array}{l}\text { Palbociclib or Ribociclib } \\
+ \text { palliative IR }\end{array}$ & $\begin{array}{l}\text { Hematological toxicity: neutropenia (grade } 2=12.5 \% \text {, } \\
\text { grade } 3=25 \% \text {, grade } 4=6.3 \% \text { ) }\end{array}$ & Absent \\
\hline $\begin{array}{l}\text { Figura et al. } \\
\text { [85] }\end{array}$ & $\begin{array}{l}\text { Brain metastatic } \\
\text { breast cancer } \\
(\mathrm{HR}+) \\
n=15 \\
\text { lesions }=42\end{array}$ & $\begin{array}{l}\text { Palbociclib or Abemaciclib } \\
+ \text { SBRT }\end{array}$ & $\begin{array}{l}\text { Radionecrosis ( } 2 \text { lesions, } 5 \% \text { ) } \\
\text { No neurologic toxicity or scalp toxicity }\end{array}$ & $\begin{array}{l}\text { Median OS } 36.7 \text { months } \\
\text { Six-month local control } \\
(88 \%) \\
\text { Six-month distant brain } \\
\text { control }(61 \%)\end{array}$ \\
\hline $\begin{array}{l}\text { Chowd-hary } \\
\text { et al. [86] }\end{array}$ & $\begin{array}{l}\text { Metastatic breast } \\
\text { cancer } \\
(\text { HR+/HER2-) } \\
n=16\end{array}$ & $\begin{array}{l}\text { Palbociclib + Fulvestrant } \\
\text { or Letrozole + palliative IR }\end{array}$ & $\begin{array}{l}\text { Hematological toxicity: grade } 1=87.5 \% \text {, grade } 2=12.5 \% \\
\text { No grade } 2 \text { or higher cutaneous, neurologic, or } \\
\text { gastrointestinal toxicity }\end{array}$ & $\begin{array}{l}\text { Local control and pain } \\
\text { relief (100\%) }\end{array}$ \\
\hline
\end{tabular}


in combination with CDK4/6 inhibitors. Several studies demonstrated that CDK4/6 inhibitors were not only efficacious for advanced or metastatic breast cancer patients but also showed promise for early breast cancer patients $[89,90]$. Thus, combination therapy still exhibits promising application prospects despite the risks of severe adverse events. In summary, our data provide a strong rationale for the clinical application of CDK4/6 inhibitors as radiation modifiers. However, more work remains to be done to achieve optimal clinical impacts.

\section{Abbreviations}

ATM: Ataxia telangiectasia mutated; ATRT: Atypical teratoid rhabdoid tumor; BSG: Brainstem Glioma; CCA: Cholangiocarcinoma; CDK4/6: Cyclin-dependent kinases 4 and 6; CGAS: Cyclic GMP-AMP synthase; CXCL1: Chemokine (C-X-C motif) ligand 1; DC: Dendritic cell; DDR: DNA damage repair; DEF: Radiation dose enhancement factor; DIPG: Diffuse intrinsic pontine glioma; DMF: Radiation dose modifying factor; DSB: Double-strand break; EAC: Esophageal adenocarcinoma; HCC: Hepatocellular carcinoma; HGG: High grade glioma; HNSCC: Head and neck squamous cell carcinoma; HR: Homologous recombination; IL-2: Interleukin-2; IL-6: Interleukin-6; IL8: Interleukin-8; IMRT: Intensity modulated radiation therapy; IR: Ionizing radiation; MBC: Metastatic breast cancer; mTORC1: Mammalian target of rapamycin complex 1; NFAT: Nuclear factor of activated T cells; NHEJ: Nonhomologous end joining; NPC: Nasopharyngeal carcinoma; NSCLC: Nonsmall cell lung cancer; $\mathrm{p}-\mathrm{H} 3$ : Phosphorylated histone 3; RB: Retinoblastoma; ROS: Reactive oxygen species; SA- $\beta$-gal: Senescence-associated $\beta$ galactosidase; SASP: Senescence-associated secretory phenotype SBRT: Stereotactic body radiation therapy; SER: Sensitizer enhancement ratio; $\mathrm{SER}_{10}$ : Sensitizer enhancement ratio at 10\% survival; SER 50 : Sensitizer enhancement ratio at 50\% survival; $\mathrm{SF}_{2}$ : Survival fraction at $2 \mathrm{~Gy}$; SSB: Singlestrand break; STING: Stimulator of interferon genes; TNBC: Triple-negative breast cancer; Treg: Regulatory T cells; TSC2: Tuberous sclerosis complex 2

\section{Acknowledgements}

Not applicable.

\section{Authors' contributions}

YLY and JRL drafted the first copy. XLY and XMG conceived this work. XXC and ZZY participated in the literature research. XM and JLM prepared the figures and Tables. ZZ prepared the manuscript for submission. All authors read and approved the final manuscript.

\section{Funding}

This work was supported by the National Natural Science Foundation of China (Grant Number. 81972846 and 81872457).

\section{Availability of data and materials}

Not applicable.

\section{Ethics approval and consent to participate}

Not applicable.

\section{Consent for publication}

Not applicable.

\section{Competing interests}

The authors declare that they have no competing interests.

\section{Author details}

${ }^{1}$ Department of Radiation Oncology, Fudan University Shanghai Cancer Center, 270 DongAn Road, Shanghai 200032, China. ²Department of Oncology, Shanghai Medical College, Fudan University, Shanghai 200032, China.
Received: 11 June 2020 Accepted: 28 August 2020

Published online: 15 September 2020

\section{References}

1. Moding EJ, Kastan MB, Kirsch DG. Strategies for optimizing the response of cancer and normal tissues to radiation. Nat Rev Drug Discov. 2013;12(7): 526-42.

2. Salehifar $E$, Hosseinimehr SJ. The use of cyclooxygenase-2 inhibitors for improvement of efficacy of radiotherapy in cancers. Drug Discov Today. 2016;21(4):654-62.

3. Negi P, Kingsley PA, Srivastava H, Sharma SK. Three weekly versus weekly Cisplatin as radiosensitizer in head and neck cancer: a decision dilemma. Asian Pac J Cancer Prev. 2016:17(4):1617-23.

4. Seiwert TY, Salama JK, Vokes EE. The concurrent chemoradiation paradigm-general principles. Nat Clin Pract Oncol. 2007:4(2):86-100.

5. Buckley AM, Lynam-Lennon N, O'Neill H, O'Sullivan J. Targeting hallmarks of cancer to enhance radiosensitivity in gastrointestinal cancers. Nat Rev Gastroenterol Hepatol. 2020;17(5):298-313.

6. Bosco EE, Knudsen ES. RB in breast cancer: at the crossroads of tumorigenesis and treatment. Cell Cycle. 2007;6(6):667-71.

7. Knudsen ES, Wang JY. Targeting the RB-pathway in cancer therapy. Clin Cancer Res. 2010;16(4):1094-9.

8. VanArsdale T, Boshoff C, Arndt KT, Abraham RT. Molecular pathways: targeting the Cyclin D-CDK4/6 Axis for cancer treatment. Clin Cancer Res. 2015;21(13):2905-10.

9. Goel S, DeCristo MJ, McAllister SS, Zhao JJ. CDK4/6 inhibition in cancer: beyond cell cycle arrest. Trends Cell Biol. 2018;28(11):911-25.

10. Lim S, Kaldis P. Cdks, cyclins and CKls: roles beyond cell cycle regulation. Development. 2013;140(15):3079-93.

11. Ingham M, Schwartz GK. Cell-cycle therapeutics come of age. J Clin Oncol. 2017:35(25):2949-59.

12. O'Leary B, Finn RS, Turner NC. Treating cancer with selective CDK4/6 inhibitors. Nat Rev Clin Oncol. 2016;13(7):417-30.

13. Lynce F, Shajahan-Haq AN, Swain SM. CDK4/6 inhibitors in breast cancer therapy: current practice and future opportunities. Pharmacol Ther. 2018; 191:65-73.

14. Klein ME, Kovatcheva M, Davis LE, Tap WD, Koff A. CDK4/6 inhibitors: the mechanism of action may not be as simple as once thought. Cancer Cell. 2018;34(1):9-20.

15. Fumagalli D, Wilson TR, Salgado R, Lu X, Yu J, O'Brien C, et al. Somatic mutation, copy number and transcriptomic profiles of primary and matched metastatic estrogen receptor-positive breast cancers. Ann Oncol. 2016; 27(10):1860-6.

16. Lundgren K, Holm K, Nordenskjold B, Borg A, Landberg G. Gene products of chromosome 11q and their association with CCND1 gene amplification and tamoxifen resistance in premenopausal breast cancer. Breast Cancer Res. 2008;10(5):R81.

17. Finn RS, Liu Y, Zhu Z, Martin M, Rugo HS, Dieras V, et al. Biomarker analyses of response to cyclin-dependent kinase $4 / 6$ inhibition and endocrine therapy in women with treatment-naive metastatic breast cancer. Clin Cancer Res. 2020;26(1):110-21.

18. Gopalan PK, Pinder MC, Chiappori A, Ivey AM, Villegas AG, Kaye FJ. A phase II clinical trial of the CDK 4/6 inhibitor palbociclib (PD 0332991) in previously treated, advanced non-small cell lung cancer (NSCLC) patients with inactivated CDKN2A. J Clin Oncol. 2014;32(15 suppl):8077.

19. Goldman JW, Gandhi L, Patnaik A, Rosen LS, Hilton JF, Papadopoulos KP, et al. Clinical activity of LY2835219, a novel cell cycle inhibitor selective for CDK4 and CDK6, in patients with non-small cell lung cancer. J Clin Oncol. 2014:32(15 suppl):8026.

20. Narayan V, Hwang WT, Lal P, Rosen MA, Gallagher M, O'Dwyer PJ, et al. Cyclin-dependent kinase 4/6 inhibition for the treatment of unresectable mature teratoma: long-term follow-up of a phase II study. Clin Genitourin Cancer. 2016;14(6):504-10.

21. Tripathy D, Im SA, Colleoni M, Franke F, Bardia A, Harbeck N, et al. Ribociclib plus endocrine therapy for premenopausal women with hormone-receptorpositive, advanced breast cancer (MONALEESA-7): a randomised phase 3 trial. Lancet Oncol. 2018;19(7):904-15.

22. Sledge GW Jr, Toi M, Neven P, Sohn J, Inoue $K$, Pivot $X$ et al. MONARCH 2: Abemaciclib in combination with fulvestrant in women with HR+/HER2 advanced breast cancer who had progressed while receiving endocrine therapy. J Clin Oncol. 2017;35(25):2875-84. 
23. Slamon DJ, Neven P, Chia S, Fasching PA, De Laurentiis M, Im SA, et al. Phase III randomized study of ribociclib and fulvestrant in hormone receptor-positive, human epidermal growth factor receptor 2-negative advanced breast cancer: MONALEESA-3. J Clin Oncol. 2018;36(24):2465-72.

24. Goetz MP, Toi M, Campone M, Sohn J, Paluch-Shimon S, Huober J, et al. MONARCH 3: Abemaciclib as initial therapy for advanced breast cancer. J Clin Oncol. 2017;35(32):3638-46.

25. Cristofanilli M, Turner NC, Bondarenko I, Ro J, Im SA, Masuda N, et al. Fulvestrant plus palbociclib versus fulvestrant plus placebo for treatment of hormone-receptor-positive, HER2-negative metastatic breast cancer that progressed on previous endocrine therapy (PALOMA-3): final analysis of the multicentre, double-blind, phase 3 randomised controlled trial. Lancet Oncol. 2016;17(4):425-39.

26. Finn RS, Martin M, Rugo HS, Jones S, Im SA, Gelmon K, et al. Palbociclib and Letrozole in advanced breast cancer. N Engl J Med. 2016;375(20):1925-36.

27. Wong $\mathrm{CH}, \mathrm{Ma}$ BBY, Hui CWC, Lo KW, Hui EP, Chan ATC. Preclinical evaluation of ribociclib and its synergistic effect in combination with alpelisib in nonkeratinizing nasopharyngeal carcinoma. Sci Rep. 2018;8(1):8010.

28. Vora SR, Juric D, Kim N, Mino-Kenudson M, Huynh T, Costa C, et al. CDK 4/6 inhibitors sensitize PIK3CA mutant breast cancer to PI3K inhibitors. Cancer Cell. 2014;26(1):136-49.

29. Teo ZL, Versaci S, Dushyanthen S, Caramia F, Savas P, Mintoff CP, et al. Combined CDK4/6 and PI3Kalpha inhibition is synergistic and immunogenic in triple-negative breast cancer. Cancer Res. 2017;77(22):6340-52.

30. Tao Z, Le Blanc JM, Wang C, Zhan T, Zhuang H, Wang P, et al. Coadministration of trametinib and palbociclib radiosensitizes KRAS-mutant non-small cell lung cancers in vitro and in vivo. Clin Cancer Res. 2016;22(1):122-33.

31. Chen SH, Gong X, Zhang Y, Van Horn RD, Yin T, Huber L, et al. RAF inhibitor LY3009120 sensitizes RAS or BRAF mutant cancer to CDK4/6 inhibition by abemaciclib via superior inhibition of phospho-RB and suppression of cyclin D1. Oncogene. 2018;37(6):821-32.

32. Ziemke EK, Dosch JS, Maust JD, Shettigar A, Sen A, Welling TH, et al. Sensitivity of KRAS-mutant colorectal cancers to combination therapy that cotargets MEK and CDK4/6. Clin Cancer Res. 2016;22(2):405-14.

33. Zacharek SJ, Xiong Y, Shumway SD. Negative regulation of TSC1-TSC2 by mammalian D-type cyclins. Cancer Res. 2005;65(24):11354-60.

34. Imperial R, Toor OM, Hussain A, Subramanian J, Masood A. Comprehensive pancancer genomic analysis reveals (RTK)-RAS-RAF-MEK as a key dysregulated pathway in cancer: its clinical implications. Semin Cancer Biol. 2019:54:14-28

35. Ma L, Chen Z, Erdjument-Bromage H, Tempst P, Pandolfi PP. Phosphorylation and functional inactivation of TSC2 by Erk implications for tuberous sclerosis and cancer pathogenesis. Cell. 2005;121(2):179-93.

36. Roux PP, Ballif BA, Anjum R, Gygi SP, Blenis J. Tumor-promoting phorbol esters and activated Ras inactivate the tuberous sclerosis tumor suppressor complex via p90 ribosomal S6 kinase. Proc Natl Acad Sci U S A. 2004; 101(37):13489-94.

37. Dean JL, McClendon AK, Knudsen ES. Modification of the DNA damage response by therapeutic CDK4/6 inhibition. J Biol Chem. 2012;287(34): 29075-87.

38. Finn RS, Crown JP, Lang I, Boer K, Bondarenko IM, Kulyk SO, et al. The cyclin-dependent kinase $4 / 6$ inhibitor palbociclib in combination with letrozole versus letrozole alone as first-line treatment of oestrogen receptorpositive, HER2-negative, advanced breast cancer (PALOMA-1/TRIO-18): a randomised phase 2 study. Lancet Oncol. 2015;16(1):25-35.

39. Cancer Genome Atlas N. Comprehensive molecular portraits of human breast tumours. Nature. 2012;490(7418):61-70.

40. Pestell RG. New roles of cyclin D1. Am J Pathol. 2013;183(1):3-9.

41. Whiteway SL, Harris PS, Venkataraman S, Alimova I, Birks DK, Donson AM, et al. Inhibition of cyclin-dependent kinase 6 suppresses cell proliferation and enhances radiation sensitivity in medulloblastoma cells. J Neuro-Oncol. 2013;111(2):113-21.

42. Hashizume R, Zhang A, Mueller S, Prados MD, Lulla RR, Goldman S, et al. Inhibition of DNA damage repair by the CDK4/6 inhibitor palbociclib delays irradiated intracranial atypical teratoid rhabdoid tumor and glioblastoma xenograft regrowth. Neuro-Oncology. 2016;18(11):1519-28.

43. Whittaker S, Madani D, Joshi S, Chung SA, Johns T, Day B, et al. Combination of palbociclib and radiotherapy for glioblastoma. Cell Death Dis. 2017;3:17033.

44. Naz S, Sowers A, Choudhuri R, Wissler M, Gamson J, Mathias A, et al. Abemaciclib, a selective CDK4/6 inhibitor, enhances the radiosensitivity of non-small cell lung cancer in vitro and in vivo. Clin Cancer Res. 2018;24(16):3994-4005.
45. Huang CY, Hsieh FS, Wang CY, Chen LJ, Chang SS, Tsai MH, et al. Palbociclib enhances radiosensitivity of hepatocellular carcinoma and cholangiocarcinoma via inhibiting ataxia telangiectasia-mutated kinasemediated DNA damage response. Eur J Cancer. 2018;102:10-22.

46. Xie X, Zheng W, Chen T, Lin W, Liao Z, Liu J, et al. CDK4/6 inhibitor palbociclib amplifies the radiosensitivity to nasopharyngeal carcinoma cells via mediating apoptosis and suppressing DNA damage repair. Onco Targets Ther. 2019;12:11107-17.

47. Gottgens EL, Bussink J, Leszczynska KB, Peters H, Span PN, Hammond EM. Inhibition of CDK4/CDK6 enhances radiosensitivity of HPV negative head and neck squamous cell carcinomas. Int J Radiat Oncol Biol Phys. 2019; 105(3):548-58

48. Tai TS, Lin PM, Wu CF, Hung SK, Huang Cl, Wang CC, et al. CDK4/6 inhibitor LEE011 is a potential radiation-sensitizer in head and neck squamous cell carcinoma: an in vitro study. Anticancer Res. 2019;39(2):713-20.

49. Fernandez-Aroca DM, Roche O, Sabater S, Pascual-Serra R, Ortega-Muelas M, Sanchez Perez I, et al. P53 pathway is a major determinant in the radiosensitizing effect of Palbociclib: implication in cancer therapy. Cancer Lett. 2019;451:23-33.

50. Li F, Xu Y, Liu B, Singh PK, Zhao W, Jin J, et al. YAP1-mediated CDK6 activation confers radiation resistance in esophageal cancer - rationale for the combination of YAP1 and CDK4/6 inhibitors in esophageal cancer. Clin Cancer Res. 2019;25(7):2264-77.

51. Ogawa K, Yoshioka Y, Isohashi F, Seo Y, Yoshida K, Yamazaki H. Radiotherapy targeting cancer stem cells: current views and future perspectives. Anticancer Res. 2013;33(3):747-54.

52. Barton KL, Misuraca K, Cordero F, Dobrikova E, Min HD, Gromeier M, et al. PD0332991, a CDK4/6 inhibitor, significantly prolongs survival in a genetically engineered mouse model of brainstem glioma. PLoS One. 2013;8(10):e77639.

53. Goldstein M, Kastan MB. The DNA damage response: implications for tumor responses to radiation and chemotherapy. Annu Rev Med. 2015;66:129-43.

54. Morgan MA, Lawrence TS. Molecular pathways: overcoming radiation resistance by targeting DNA damage response pathways. Clin Cancer Res. 2015;21(13):2898-904.

55. Willers H, Gheorghiu L, Liu Q, Efstathiou JA, Wirth LJ, Krause M, et al. DNA damage response assessments in human tumor samples provide functional biomarkers of radiosensitivity. Semin Radiat Oncol. 2015;25(4):237-50.

56. Mirman Z, de Lange T. 53BP1: a DSB escort. Genes Dev. 2020;34(1-2):7-23.

57. Jin MH, Oh DY. ATM in DNA repair in cancer. Pharmacol Ther. 2019;203:107391.

58. Willers H, Dahm-Daphi J, Powell SN. Repair of radiation damage to DNA. Br J Cancer. 2004;90(7):1297-301.

59. Gudkov AV, Komarova EA. The role of p53 in determining sensitivity to radiotherapy. Nat Rev Cancer. 2003;3(2):117-29.

60. Pavlopoulou A, Bagos PG, Koutsandrea V, Georgakilas AG. Molecular determinants of radiosensitivity in normal and tumor tissue: a bioinformatic approach. Cancer Lett. 2017:403:37-47.

61. Hagen KR, Zeng X, Lee MY, Tucker Kahn S, Harrison Pitner MK, Zaky SS, et al Silencing CDK4 radiosensitizes breast cancer cells by promoting apoptosis. Cell Div. 2013;8(1):10.

62. Preuss U, Landsberg G, Scheidtmann $\mathrm{KH}$. Novel mitosis-specific phosphorylation of histone $\mathrm{H} 3$ at Thr11 mediated by DIk/ZIP kinase. Nucleic Acids Res. 2003;31(3):878-85.

63. Thangavel C, Dean JL, Ertel A, Knudsen KE, Aldaz CM, Witkiewicz AK, et al. Therapeutically activating RB: reestablishing cell cycle control in endocrine therapy-resistant breast cancer. Endocr Relat Cancer. 2011;18(3):333-45.

64. Rader J, Russell MR, Hart LS, Nakazawa MS, Belcastro LT, Martinez D, et al. Dual CDK4/CDK6 inhibition induces cell-cycle arrest and senescence in neuroblastoma. Clin Cancer Res. 2013;19(22):6173-82.

65. Yoshida A, Lee EK, Diehl JA. Induction of therapeutic senescence in Vemurafenib-resistant melanoma by extended inhibition of CDK4/6. Cancer Res. 2016;76(10):2990-3002.

66. Lopez-Otin C, Blasco MA, Partridge L, Serrano M, Kroemer G. The hallmarks of aging. Cell. 2013;153(6):1194-217.

67. Munoz-Espin D, Serrano M. Cellular senescence: from physiology to pathology. Nat Rev Mol Cell Biol. 2014;15(7):482-96.

68. Mavrogonatou E, Pratsinis $\mathrm{H}$, Kletsas D. The role of senescence in cancer development. Semin Cancer Biol. 2020;62:182-91.

69. Hernandez-Segura A, Nehme J, Demaria M. Hallmarks of cellular senescence. Trends Cell Biol. 2018;28(6):436-53.

70. Mirzayans R, Scott A, Cameron M, Murray D. Induction of accelerated senescence by gamma radiation in human solid tumor-derived cell lines expressing wild-type TP53. Radiat Res. 2005;163(1):53-62. 
71. Jones KR, Elmore LW, Jackson-Cook C, Demasters G, Povirk LF, Holt SE, et al. p53-dependent accelerated senescence induced by ionizing radiation in breast tumour cells. Int J Radiat Biol. 2005;81(6):445-58.

72. Faget DV, Ren Q, Stewart SA. Unmasking senescence: context-dependent effects of SASP in cancer. Nat Rev Cancer. 2019;19(8):439-53.

73. Weichselbaum RR, Liang H, Deng L, Fu YX. Radiotherapy and immunotherapy: a beneficial liaison? Nat Rev Clin Oncol. 2017;14(6):365-79.

74. Petroni G, Formenti SC, Chen-Kiang S, Galluzzi L. Immunomodulation by anticancer cell cycle inhibitors. Nat Rev Immunol. 2020. https://doi.org/10. 1038/s41577-020-0300-y.

75. Goel S, DeCristo MJ, Watt AC, BrinJones H, Sceneay J, Li BB, et al. CDK4/6 inhibition triggers anti-tumour immunity. Nature. 2017;548(7668):471-5.

76. Sharabi AB, Lim M, DeWeese TL, Drake CG. Radiation and checkpoint blockade immunotherapy: radiosensitisation and potential mechanisms of synergy. Lancet Oncol. 2015;16(13):e498-509.

77. Gupta A, Probst HC, Vuong V, Landshammer A, Muth S, Yagita H, et al. Radiotherapy promotes tumor-specific effector CD8+ T cells via dendritic cell activation. J Immunol. 2012;189(2):558-66.

78. Deng J, Wang ES, Jenkins RW, Li S, Dries R, Yates K, et al. CDK4/6 inhibition augments antitumor immunity by enhancing T-cell activation. Cancer Discov. 2018;8(2):216-33.

79. Schaer DA, Beckmann RP, Dempsey JA, Huber L, Forest A, Amaladas N, et al. The CDK4/6 inhibitor Abemaciclib induces a T cell inflamed tumor microenvironment and enhances the efficacy of PD-L1 checkpoint blockade. Cell Rep. 2018;22(11):2978-94.

80. Lhuillier C, Rudqvist N-P, Elemento O, Formenti SC, Demaria S. Radiation therapy and anti-tumor immunity: exposing immunogenic mutations to the immune system. Genome Med. 2019;11(1):40.

81. Lugade AA, Moran JP, Gerber SA, Rose RC, Frelinger JG, Lord EM. Local radiation therapy of B16 melanoma tumors increases the generation of tumor antigenspecific effector cells that traffic to the tumor. J Immunol. 2005;174(12):7516-23.

82. Lee $Y$, Auh SL, Wang $Y$, Burnette $B$, Wang $Y$, Meng $Y$, et al. Therapeutic effects of ablative radiation on local tumor require CD8+ T cells: changing strategies for cancer treatment. Blood. 2009;114(3):589-95.

83. Hans S, Cottu P, Kirova YM. Preliminary results of the association of Palbociclib and radiotherapy in metastatic breast cancer patients. Radiother Oncol. 2018;126(1):181.

84. Ippolito E, Greco C, Silipigni S, Dell'Aquila E, Petrianni GM, Tonini G, et al. Concurrent radiotherapy with palbociclib or ribociclib for metastatic breast cancer patients: preliminary assessment of toxicity. Breast. 2019;46:70-4.

85. Figura NB, Potluri TK, Mohammadi H, Oliver DE, Arrington JA, Robinson TJ, et al. CDK 4/6 inhibitors and stereotactic radiation in the management of hormone receptor positive breast cancer brain metastases. J Neuro-Oncol. 2019;144(3):583-9.

86. Chowdhary M, Sen N, Chowdhary A, Usha L, Cobleigh MA, Wang D, et al. Safety and efficacy of Palbociclib and radiation therapy in patients with metastatic breast cancer: initial results of a novel combination. Adv Radiat Oncol. 2019;4(3):453-7.

87. Messer JA, Ekinci E, Patel TA, Teh BS. Enhanced dermatologic toxicity following concurrent treatment with palbociclib and radiation therapy: a case report. Rep Pract Oncol Radiother. 2019;24(3):276-80.

88. Kawamoto T, Shikama N, Sasai K. Severe acute radiation-induced enterocolitis after combined palbociclib and palliative radiotherapy treatment. Radiother Oncol. 2019;131:240-1.

89. Hurvitz SA, Martin M, Press MF, Chan D, Fernandez-Abad M, Petru E, et al. Potent cell-cycle inhibition and Upregulation of immune response with Abemaciclib and Anastrozole in neoMONARCH, phase II Neoadjuvant study in HR(+)/HER2(-) breast Cancer. Clin Cancer Res. 2020;26(3):566-80.

90. Colwell J. Abemaciclib shows promise for early breast cancer. Cancer Discov. 2017;7(2):119-20.

\section{Publisher's Note}

Springer Nature remains neutral with regard to jurisdictional claims in published maps and institutional affiliations.

Ready to submit your research? Choose BMC and benefit from:

- fast, convenient online submission

- thorough peer review by experienced researchers in your field

- rapid publication on acceptance

- support for research data, including large and complex data types

- gold Open Access which fosters wider collaboration and increased citations

- maximum visibility for your research: over $100 \mathrm{M}$ website views per year

At BMC, research is always in progress.

Learn more biomedcentral.com/submissions 